\title{
Роль ионной формы анионообменника при необменной сорбции фенилаланина
}

\author{
Каширцева Е.Р., Хохлов В.Ю., Хохлова О.Н. \\ ФГБОУ ВО «Воронежский государственный университет», Воронеж
}

Поступила в редакцию 20.02.2018 г.

DOI: https://doi.org/10.17308/sorpchrom.2018.18/496

Рассмотрена необменная сорбция фенилаланина из водных растворов анионообменником АВ-17-2П в различных ионных формах. Показано, что при использовании сорбента с противоионом одной природы, определяющим фактором при сорбции является гидратация противоиона. При использовании анионита в ионных формах различной природы сорбция аминокислоты определяется строением противоиона и его способностью к дополнительным взаимодействиям вплоть до смены механизма поглощения.

Ключевые слова: ионные формы, гидратация противоиона, фенилаланин, высокоосновный анионообменник, необменное поглощение.

\section{The role of the ionic form of the ion exchanger at the non-exchange sorption of phenylalanine}

\author{
Kashirtseva E.R., Khokhlova O.N., Khokhlov V.Yu \\ Voronezh State University, Voronezh
}

For identification of features of fixing of substances in the ion exchanger at not exchange sorption, and also the choice of optimum conditions for division of multicomponent mixes, it is necessary to investigate various ionic forms of a sorbent. The non-exchange sorption of phenylalanine from aqueous solutions by anion exchanger AV-17-2P in different ionic forms: similar $\left(\mathrm{F}^{-}, \mathrm{Cl}^{-}, \mathrm{Br}^{-}, \mathrm{I}^{-}\right)$and different $\left(\mathrm{Cl}^{-}, \mathrm{OH}^{-}, \mathrm{NO}_{3}^{-}\right.$, $\left.\mathrm{Phe}^{-}\right)$is considered.

In water solution phenylalanine is present at a type of bipolar ions, and use of the anion exchanger in a salt form excludes a recharge and ion-exchange fixing of amino acid, thus, in system not exchange absorption proceeds. Isotherms of sorption of phenylalanine on the AV-17-2P anion exchanger in various ionic forms are received and discussed. Influence of a mitselloobrazovaniye of phenylalanine in solution by sight of isotherms and amino acid absorption size is considered. It is shown that on the AV-17-2P anion exchanger in the ionic forms which are characterized by good swelling, the mitselloobrazovaniye in solution has no significant effect on a type of isotherms and size of sorption of phenylalanine. In work influence of various amount of water in a phase of a sorbent, ability to hydration, the size, geometry, density and localization of a charge on interpartial interactions in a sorbent phase is discussed at not exchange sorption of phenylalanine by the AV-17-2P anion exchanger.

It is revealed that when using a sorbent with the antiion of one nature (halogenide ions) determining by a factor at sorption hydration of an antiion is. When using $\mathrm{OH}$ - forms of a sorbent occurs change of the mechanism of absorption of phenylalanine as in a phase of an ionite the recharge of a bipolar ion of amino acid in anion and electrostatic interaction with functional group proceeds, i.e. ionic exchange with a recharge proceeds. When using the anionit in ionic forms of various nature sorption is defined by a structure of an antiion and its ability to additional interactions, up to change of the mechanism of absorption. Increase in the size of an antiion promotes deterioration in sorption of amino acid, and increase in hydration and additional hydrophobic interactions with an antiion in a sorbent promote the best sorption of the tsvitterlit. 
Keywords: ionic form, hydration counterion, phenylalanine, high basic anion exchanger, nonexchange sorption.

\section{Введение}

Для выявления особенностей закрепления веществ в ионообменнике при необменной сорбции, а так же выбора оптимальных условий для разделения многокомпонентных смесей, необходимо исследовать различные ионные формы сорбента Имея разный противоион, ионообменники содержат различное количество воды, в том числе, свободной и связанной $[1,2]$. Сами же противоионы при одинаковом заряде имеют различный размер, геометрию, плотность и локализацию заряда, а так же гидратацию $[3,4]$. Перечисленные факторы различным образом влияют на межчастичные взаимодействия в фазе сорбента, особенно при необменной сорбции, поскольку в этом случае в системе отсутствует доминирующая сила, такая как кулоновские взаимодействия при ионном обмене, и определяющим является комплекс факторов, действующих разнонаправленно. Поэтому целью работы являлось исследование необменной сорбции фенилаланина на анионообменнике АВ-17-2П в различных ионных формах $\left(\mathrm{F}^{-}, \mathrm{Cl}^{-}, \mathrm{Br}^{-}, \mathrm{I}, \mathrm{OH}^{-}, \mathrm{NO}_{3}^{-}, \mathrm{Phe}^{-}\right)$.

\section{Эксперимент}

В работе в качестве сорбента использован высокоосновный, хорошо набухающий стиролдивинилбензольный анионообменник АВ-17-2П, имеющий в качестве функциональных групп четвертичный азот, для получения различных ионных форм которого использовали стандартные методики [5]. В качестве сорбата использовали ароматическую аминокислоту фенилаланин амино-карбоксильной группировки и бензольного кольца в боковом радикале приводит к возможности поглощения за счет взаимодействий различной природы.

Таблица. Некоторые физико-химические характеристики противоионов

\begin{tabular}{|c|c|c|c|c|c|c|c|}
\hline \multirow{2}{*}{ Характеристика } & \multicolumn{7}{|c|}{ Противоион } \\
\hline & $\mathrm{F}^{-}$ & $\mathrm{Cl}^{-}$ & $\mathrm{Br}^{-}$ & $\mathrm{I}^{-}$ & $\mathrm{OH}^{-}$ & $\mathrm{NO}_{3}^{-}$ & $\mathrm{Phe}^{-}$ \\
\hline 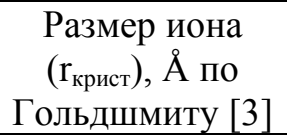 & 1.33 & 1.81 & 1.96 & 2.20 & $\begin{array}{c}1.32-1.4 \\
{[4]}\end{array}$ & 2.50 & $\begin{array}{c}\mathrm{a}=26.68 \\
\mathrm{~b}=6.98 \\
\mathrm{c}=5.34\end{array}$ \\
\hline $\begin{array}{c}\text { Число гидрата- } \\
\text { ции (h) [4] }\end{array}$ & 7 & 5 & 5 & 4 & 4 & 6 & $(3+4) * *$ \\
\hline $\begin{array}{c}\text { Особенности } \\
\text { гидратации иона }\end{array}$ & $\begin{array}{l}\text { Положи- } \\
\text { тельная[4] }\end{array}$ & $\begin{array}{r}\text { Отр } \\
\text { Ги }\end{array}$ & $\begin{array}{l}\text { цател } \\
\text { цатал } \\
{[4]}\end{array}$ & & $\begin{array}{c}\text { Положи- } \\
\text { тельная }\end{array}$ & $\begin{array}{c}\text { Отрицатель- } \\
\text { ная } \\
\text { Гидратация } \\
\text { [4] }\end{array}$ & $\begin{array}{c}\text { Только ами- } \\
\text { но- } \\
\text { карбоксиль- } \\
\text { ная группи- } \\
\text { ровка }\end{array}$ \\
\hline $\begin{array}{c}\text { Особенности } \\
\text { геометрии иона }\end{array}$ & Сфери & ескаs & рорм & & Линейный & $\begin{array}{c}\text { Треугольная } \\
\text { форма }\end{array}$ & $\begin{array}{c}\text { Дифильный } \\
\text { биполярный } \\
\text { ион }\end{array}$ \\
\hline
\end{tabular}

*размеры ячейки в кристаллической решетке [6];** Число гидратации карбоксильной и амино- групп [7]

Сорбцию фенилаланина анионообменником проводили из водных растворов в статических условиях в диапазоне концентраций 0.005-0.04 моль/дм³. Анализ исход- 
ных и равновесных растворов на содержание аминокислоты проводили спектрофотометрически при длине волны 257 нм. Содержание фенилаланина в сорбенте рассчитывали по разности концентраций раствора до и после сорбции аминокислотыс учетом объема и массы контактирующих фаз. Некоторые свойства анионов, выступающих в качестве противоионов в исследуемом анионообменнике, представлены в таблице.

\section{Обсуждение результатов}

Изучена сорбция фенилаланина анионообменником, в котором противоионами являлись галогенид-ионы. Это анионы, размер которых нарастает в ряду $\mathrm{F}<\mathrm{Cl}^{-}$ $<B r^{-}<I^{-}$, а плотность заряда соответственно уменьшается; при этом гидратация характеризуется рядом $F^{-}>C l^{-}>B r^{-}>I$, и определяет ряд набухаемости анионитов [1-8]. Необходимо отметить, что в водном растворе фенилаланин присутствует в виде биполярных ионов, а использование анионообменника в галогенидной форме исключает перезарядку и ионообменное закрепление аминокислоты, таким образом, в системе протекает необменное поглощение.

На рис. 1 представлены изотермы сорбции фенилаланина анионообменником AB-17-2П в форме галогенид-ионов. Как видно из рисунка, для всех используемых ионных форм сорбента на изотермах сорбции в области концентраций 0.02-0.03 моль/дм ${ }^{3}$ наблюдается незначительный перегиб, наиболее выраженный для менее набухающих форм сорбента. Это объясняется мицеллообразованием фенилаланина в растворе в области концентраций выше 0.022 моль/дм ${ }^{3}$ [7-9], которое может конкурировать с другими процессами связывания в системе, в том числе с сорбцией. Наличие пор в рассматриваемом анионообменнике приводит к возможности поглощения фенилаланина после ККМ, в то время как на низкоосновных малонабухающих сорбентах наблюдается падение сорбции [10].

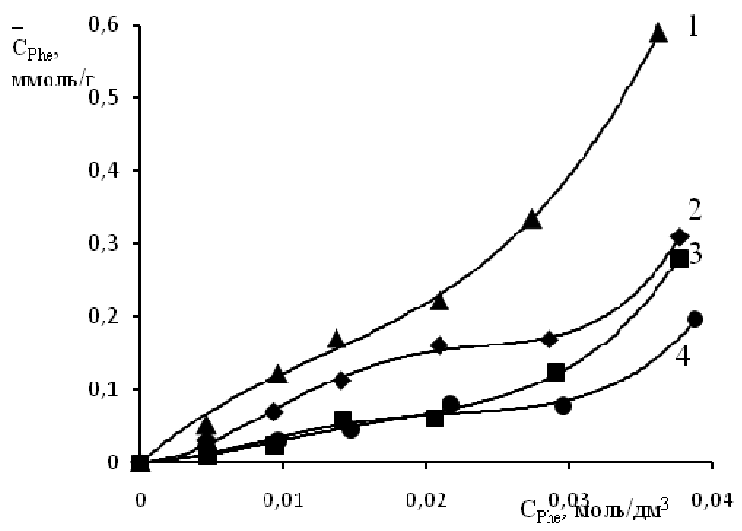

Рис. 1. Изотермы необменной сорбции фенилаланина анионообменником AB-17-2П в галогенидных ионных формах: $1-\mathrm{Cl}^{-} ; 2-\mathrm{F}^{-} ; 3-\mathrm{I}^{-} ; 4-\mathrm{Br}^{-}$

Наибольшая сорбция наблюдается для сорбента в $C l$-форме, а полученный сорбционный ряд $\mathrm{Cl}^{-}>\mathrm{F}^{-}>\mathrm{I}^{-} \geq \mathrm{Br}^{-}$не совпадает с рядами физико-химических характеристик анионов (табл.), поэтому для объяснения полученной закономерности необходимо рассматривать комплекс различных факторов, действующих одновременно.

Как показано в [11], аминокислота закрепляется в сорбенте в результате взаимодействия положительно заряженных функциональной группы ионообменника и аминогруппы аминокислоты, и отрицательно заряженных противоиона и карбоксильной группы аминокислоты, расположенных в виде четырехугольника с чередо- 
ванием положительных и отрицательных зарядов в вершинах, разделенных молекулами воды. Исходя из этого, большая плотность заряда противоиона, обусловленная его меньшим размером, приводит к более сильному взаимодействию аминогруппы аминокислоты и противоиона. Однако при сильной гидратации противоиона происходит экранирование взаимодействий разнозаряженных структурных элементов в сорбенте и ослабление сорбции, несмотря на то, что большая набухаемость сорбента приводит к лучшей способности образовывать внутренний раствор. Таким образом, для фторид-формы анионообменника, при наибольшей набухаемости и плотности заряда противоиона, большая положительная гидратация $F$ приводит к меньшей сорбции аминокислоты по сравнению с $\mathrm{Cl}$-формой сорбента.

Большой размер бромид- и иодид-ионов (малая плотность заряда), малая набухаемость сорбента, вызванная слабой отрицательной гидратацией этих противоионов, приводит к малой сорбции феналаланина на анионите в $B r^{-}$и $I^{-}$-форме. Несколько большая сорбция аминокислоты на иодид-форме сорбента при высоких концентрациях, вероятно, вызвана наименьшей гидратацией этого противоиона и отсутствием экранирования противоположно заряженных структурных элементов в фазе анионита $[4,11]$.

Таким образом, при необменной сорбции фенилаланина анионообменником в различных галогенидных ионных формах одним из основных факторов, определяющих величину сорбции, является гидратация противоиона.

В случае рассмотрения различных по природе противоионов в анионообменнике, может изменяться не только сила основных межчастичных взаимодействий, но и их природа. Поэтому нами рассмотрены $\mathrm{OH}^{-}, \mathrm{Cl}^{-}, \mathrm{NO}_{3}^{-}$, и фенилаланиновая $\left(\mathrm{Phe}^{-}\right)$ формы анионообменника AB-17-2П при поглощении биполярных ионов фенилаланина из водного раствора. Изотермы сорбции представлены на рис. 2.

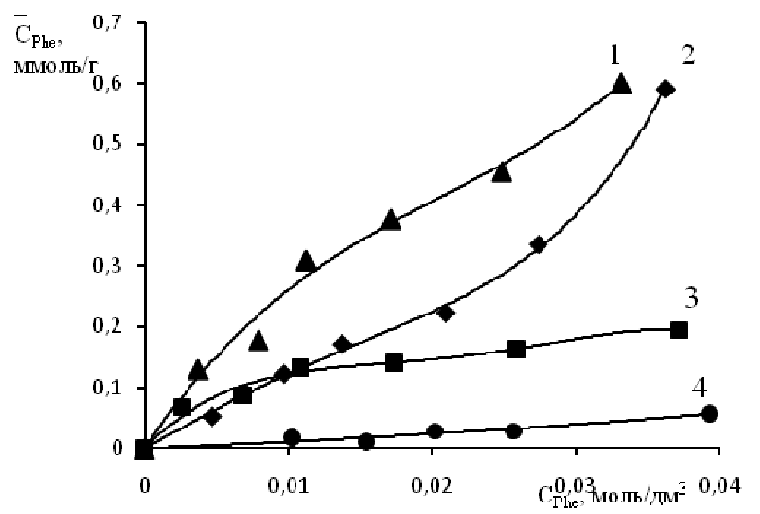

Рис. 2. Изотермы необменной сорбции фенилаланина из водного раствора анионообменником $\mathrm{AB}-17-2 П$ в различных ионных формах:

$$
1-\mathrm{Phe}^{-} ; 2-\mathrm{Cl}^{-} ; 3-\mathrm{OH}^{-} ; 4-\mathrm{NO}_{3}^{-}
$$

Как видно из рисунка, перегибы в области ККМ фенилаланина на изотермах сорбции практически отсутствуют, что свидетельствует о малом влиянии мицеллообразования в растворе на процесс сорбции в данных условиях. Сорбция фенилаланина на $\mathrm{Cl}$-форме описана выше и будет рассматриваться как основа для сравнения.

Поглощение фенилаланина на $\mathrm{NO}_{3}$-форме анионообменника меньше, чем при использовании всех остальных ионных форм анионита. Это связано с тем, что нитрат-ион крупнее всех рассматриваемых анионов, имеет меньшую плотность заряда и треугольную форму, поэтому расстояния между центрами притяжения, несущими положительный и отрицательный заряд в фазе сорбента больше, а, следовательно, сила удерживания аминокислоты меньше. 
При поглощении фенилаланина из водных растворов на $O H$-форме сорбента в фазе ионита протекает перезарядка биполярного иона аминокислоты в анион и электростатическое взаимодействие с функциональной группой, т.е. протекает ионный обмен с перезарядкой.

$$
\mathrm{R}-\mathrm{OH}^{-}+\mathrm{Phe}^{ \pm} \rightarrow \mathrm{R}-\mathrm{Phe}^{-}+\mathrm{H}_{2} \mathrm{O}
$$

Таким образом, при использовании $O H$-формы сорбента происходит изменение механизма поглощения фенилаланина. Количество поглощенной таким образом аминокислоты невелико и не превышает $10 \%$ от емкости анионообменника и выше, чем на $\mathrm{NO}_{3}$-форме, но ниже, чем на $\mathrm{Cl}$-форме сорбента. Это связано с тем, что в перезарядке аминокислоты участвует противоион $\mathrm{OH}^{-}$и протон аминогруппы фенилаланина, а в электростатическом взаимодействии с функциональной группой сорбента участвует карбоксильная группа аминокислоты, несущая отрицательный заряд. T.е. при таком механизме поглощения важную роль играет ориентационный эффект.

При рассмотрении необменной сорбции представляют особый интерес межчастичные взаимодействия в сорбенте, когда природа противоиона и сорбирующейся частицы одинакова, т.е. сорбция аминокислоты на аминокислотной форме ионообменника. Такая ситуация возникает, когда ионный обмен в системе полностью завершен, и протекает необменное (сверхэквивалентное) поглощение сорбата на новой моноионной форме ионита.

Как видно из рис. 2, поглощение фенилаланина анионообменником AB-172П, где в качестве противоиона выступают анионы этой же аминокислоты, выше, чем на минеральных ионных формах сорбента. Это, вероятно, связано с тем, что в аминокислотной ионной форме фаза сорбента содержит меньше воды, что, с одной стороны, затрудняет образование внутреннего раствора, а, с другой стороны, концентрирование фазы сорбента приводит к сближению гидрофобных структур матрицы анионита, обменно и необменно поглощенных частиц фенилаланина и реализации $\pi-\pi$ взаимодействий. Таким образом, дополнительные гидрофобные взаимодействия с противоионом в сорбенте способствуют лучшей сорбции цвиттерлита.

\section{Заключение}

При изучении необменной сорбции фенилаланина из водных растворов на анионообменнике АВ-17-2П в различных ионных формах установлено, что в сорбционных системах с противоионом одной природы $\left(\mathrm{F}^{-}, \mathrm{Cl}^{-}, \mathrm{Br}^{-}, \mathrm{I}^{-}\right)$, определяющим фактором при поглощении является гидратация противоиона, а при использовании анионита в ионных формах различной природы $\left(\mathrm{OH}^{-}, \mathrm{Cl}^{-}, \mathrm{NO}_{3}^{-}, \mathrm{Phe}^{-}\right)$сорбция аминокислоты определяется строением противоиона и его способностью к дополнительным взаимодействиям, вплоть до смены механизма поглощения.

\section{Список литературы}

1. Гельферих Ф. Иониты: Основы ионного обмена. М. : Изд-во Иностран. литер. 1962. $490 \mathrm{c}$.

2. Кокотов Ю.А., Пасечник В.А. Равновесие и кинетика ионного обмена. Л. Наука. 1977. $336 \mathrm{c}$.

3. Мищенко К.П., Равдель А.А. Краткий справочник физико-химических величин. Л. Химия. 1974. 200 с.
4. Эрдеи-Груз Т. Явления переноса в водных растворах. М. Мир. 1976. 595 с.

5. Селеменев В.Ф., Славинская Г.В., Хохлов В.Ю. Практикум по ионному обмену: Учебное пособие. Воронеж. Воронеж. гос. ун-т. 2004. $160 \mathrm{c.}$

6. Гурская Г.В. Структура аминокислот. М. Наука. 1966. 159 с. 
7. Трунаева Е.С., Хохлова О.Н., Хохлов В.Ю. // Журнал структурной химии. 2015. Т. 56. № 6. С. 1111-1115.

8. Гребенюк В.Д., Мазо А.А. Обессоливание воды ионитами. М. Химия. 1980265 с.

9. Васильева В.И., Голева Е.А., Селеменев В.Ф. // Журнал физической химии. 2016. Т. 90. № 10. С. 1548-1557.

\section{References}

1. Gelferih F., Ionity: Osnovy ionnogo obmena. M., Izd-vo Inostran. liter., 1962, 490 p.

2. Kokotov Ju.A., Pasechnik V.A. Ravnovesie i kinetika ionnogo obmena, L., Nauka, 1977, $336 \mathrm{p}$.

3. Mishhenko K.P., Ravdel A.A. Kratkij spravochnik fiziko-himicheskih velichin. L., Khimija, 1974, 200 p.

4. Erdey- Gruz T., Yavleniya perenosa v vodnykh rastvorakh. M., Mir, 1976, 595 p.

5. Selemenev V.F., Slavinskaya G.V., Khokhlov V.Yu., Praktikum po ionnomu obmenu: Uchebnoe posobie, Voronezh: Voronezh. gos. un-t, 2004, $160 \mathrm{p}$.

6. Gurskaya G.V. Struktura aminokislot. M.: Nauka, 1966. 159 s.

Каширцева Елизавета Романовна - студент 4 курса кафедры аналитической химии, Воронежский Государственный Университет, Воронеж.

Хохлова Оксана Николаевна - доцент кафедры аналитической химии, к.Х.н., Воронежский Государственный Университет, Воронеж.

Хохлов Владимир Юрьевич - профессор кафедры аналитической химии, д.Х.н., Воронежский Государственный Университет, Воронеж.
10.Хохлова О.Н., Селеменев В.Ф., Кузнецова Л.В., Хохлов В.Ю. // Журнал физической химии. 2001. Т. 75. № 11. С. 2002-2006.

11. Трунаева Е.С., Хохлова О.Н., Хохлов В.Ю. // Сорбиионные и хроматографические проиессы 2018. Т. 18. № 2. С. 142-149

7. Trunaeva E.S., Khokhlova O.N., Khokhlov V.Yu., Zhurnal strukturnoi khimii, 2015, Vol. 56, No 6, pp. 1111-1115.

8. Grebenyuk V.D., Mazo A.A., Obessolivanie vody ionitami, M., Khimiya, 1980, 256 p.

9. Vasileva V.I., Goleva E.A., Selemenev V.F., Zhurnal fizicheskoj khimii, 2016, Vol. 90, No 10, pp. 1548-1557.

10.Khokhlova O.N., Selemenev V.F., Kuznetsova L.V., Khokhlov V.Yu., Zhurnal fizicheskoj khimii, 2001, Vol. 75, No 11, pp. 2002-2006.

11.Trunaeva E.S., Khokhlova O.N., Khokhlov V.Yu., Sorbtsionnye $i$ khromatograficheskie protsessy, 2018, Vol. 18, No 2, pp. 142-149.

Kashirtseva Elizaveta R. - 4th year student, Department of analytical chemistry, Voronezh State University, Voronezh, e-mail: kashirtseva_e@mail.ru

Khokhlova Oksana N. - associate professor, department of analytical chemistry, Voronezh State University, Voronezh, e-mail: okxox@yandex.ru

Khokhlov Vladimir Yu. - professor, department of analytical chemistry, Voronezh State University, Voronezh, e-mail: vladkh70@mail.ru 